\title{
Evaluation and Determination of Heavy Metals (Mercury, Lead and Cadmium) in Human Breast Milk
}

\author{
Atousa Abdollahi $^{1}$, Fariba Tadayon ${ }^{2}$ and Mooud Amirkavei ${ }^{3}$ \\ ${ }^{1}$ Department of Environmental Chemistry, Islamic Azad University Khorasgan (Isfahan) Branch, \\ 8159-158 Isfahan, IRAN \\ 2 Department of Chemistry, Islamic Azad University North Tehran Branch,Tehran, IRAN \\ ${ }^{1}$ Department of Environmental Chemistry, Islamic Azad University Khorasgan (Isfahan) Branch, \\ 8159-158 Isfahan, IRAN
}

\begin{abstract}
Mercury, Lead and Cadmium were determined in 100 samples of human breast milk samples from urban and rural mothers in Isfahan (IRAN). A questionnaire about area of residence, nutrition, smoking habits, and dental fillings was filled out by the lactating mothers The combination of nitric acid, hydrogen peroxide and perchloric acid was found to be one of the most suitable acids in wet digestion of milk. Cold vapor atomic absorption was used to determine the mercury content in milk after wet digestion. The effect of concentration of nitric acid, influence of flow rate and $\operatorname{tin}(\Pi)$ chloride were investigated. The mean concentration of mercury in human breast milk samples was $0.96 \mathrm{ppb}$. Extraction of $\mathrm{Pb}$ and $\mathrm{Cd}$ were performed with ammonium pyrrolidine dithiocarbamate (APDC) to methyl isobutyl ketone (MIBK) and were determined by Flame Atomic Absorption Spectrometry. The factors influencing, the complex formation, $\mathrm{pH}$, time and buffer were optimized. The mean concentration of $\mathrm{Pb}$ and $\mathrm{Cd}$ in human breast milk was 0.0147 and $0.0121 \mathrm{ppm}$, respectively. The maximum concentrations were found in breast milk of rural mothers.
\end{abstract}

Keywords: Heavy metals, Mercury, Lead, Cadmium, human breast milk, Cold vapor atomic absorption, Flame Atomic Absorption Spectrometry

\section{Introduction}

Human milk is the main source of food for infants during the first four to five months of their lives. Breast milk can, however, also be a pathway of maternal excretion of toxic elements. Breast milk consists of some hazards and may include heavy metals and other contaminates, which could have harmful effects on nervous system (Massaro, 1997; Jarup, 2003; Wong and Lye, 2008). Lead and Mercury are toxic to the developing brain, lead has subtle effects on neurological functions, and including learning, memory, and attention span (Hayano et al., 1996). Pb is one of the neurotoxicants and its concentration in breast milk is mostly higher than dose of $\mathrm{Hg} . \mathrm{Pb}$ that was accumulated in the mother's bones in the past, is released along with calcium into her blood, and frequently pollutes her breast milk (Ettinger et al., 2006). It has been said that, $36-80 \%$ of all blood $\mathrm{Pb}$ in breast-fed infants comes from mother's milk during the first three months of their lives (Gulson et al., 2003). Harmful effects of mercury, include brain damage, mental retardation, seizures and inability to speak. Mothers most likely to be exposed to metallic mercury from mercury released from dental fillings. Methyl mercury can build up in certain fish to much higher levels and these fish may then be eaten by mothers (Oskarsson et al., 1996). Cadmium is toxic to the male reproductive system, the kidneys, and the brain (Hayano et al., 1996). Cd is a famous human carcinogen. It can also influence brain growth in infants, and it has been estimated that it might increase the risk of premature delivery (Nishijo et al., 2002; Jarup, 2003; Schoeters et al., 2006). Unlike Hg and $\mathrm{Pb}, \mathrm{Cd}$ is very little transferred through the placenta and only a small percentage reaches breast milk (Vather et al., 2001). Researchers found a strong correlation between the amount of toxic metals in the mother's milk samples and amount of these elements in environment and food.

There are two reasons for learning about the toxic metal levels in the breast milk: first, as a pathway of exposure, and second, as an indicator of likely prenatal exposure (Jarup, 2003).

The aims of this study were to measure $\mathrm{Cd}, \mathrm{Pb}$ and $\mathrm{Hg}$ 
concentrations in the breast milk of healthy lactating women who were living in Isfahan, a big city in Iran and rural areas and to investigate the effect of mother's age,

\section{Materials and Methods}

All reagents used were of analytical reagent grades and were purchased from the Merck Company (Darmstadt, Germany). Mercury Analyzer, model MAS-50A Perkin Elmer was used for mercury measurment.

A Perkin Elmer atomic absorption spectrometer, model 2380 was used for other metal measurements throughout this study. Perkin Elmer hollow cathode lamps for $\mathrm{Pb}, \mathrm{Cd}$ and $\mathrm{Cr}$ were used as light sources which operated, respectively, at current of 10,6 and $25 \mathrm{~mA}$, wavelength of $217,228.8$ and $357.8 \mathrm{~nm}$ with a spectra bandwidth of $0.7,0.7$ and $0.7 \mathrm{~nm}$, as recommended by manufacturers. The flame was optimized. The $\mathrm{pH}$ measurements were carried out with a Metrohm pH meter (model 632, Switzerland).

\section{Results and Discussion}

Different parameters affecting the complex formation, extraction and determination were optimized by using the uni variable approach. Four different methods of wet digestion were used to determine the matals in milk samples. The results obtained are summarized in Table 1. The effect of dilution on the recovery of $\mathrm{Pb}$ and $\mathrm{Cd}$ was studied by varying the volume in the range of $10-100 \mathrm{ml}$, and keeping the other diet, lifestyle, smoking habits in the family on the concentration of these heavy metals.

variable constant. The results demonstrated in Table 2 . The effect of $\mathrm{pH}$ on the extraction of $0.05 \mathrm{ppm}$ of $\mathrm{Pb}$ and $\mathrm{Cd}$ was studied. The results demonstrated in Fig. 1.

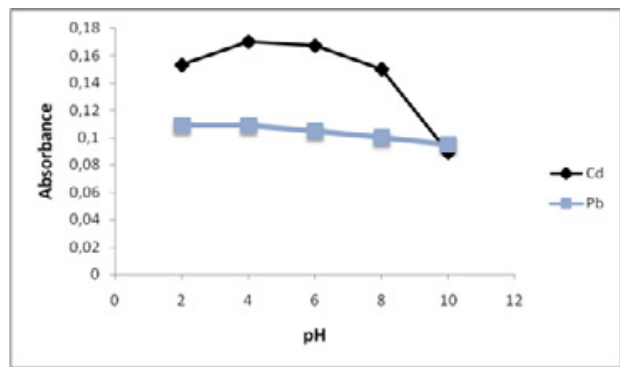

Fig. 1. The effect of $\mathrm{pH}$ on the extraction of 0.05 ppm of $\mathrm{Pb}$ and $\mathrm{Cd}$

The effect of ammonium pyrrolidine dithiocarbamate (APDC) on the extraction of $\mathrm{Pb}$ and $\mathrm{Cd}$ was also investigated. Some experiments were performed by using different volumes of APDC (2\%). The volume of $4 \mathrm{~mL}$ APDC $2 \%$ was used. The effect of the extraction time was examined in the range of $0-5$ min with constant experimental conditions. Two methods of preparation were applied to determine the mercury (Table 3 ).

The effect of flowrate and amount of $\mathrm{SnCl}_{2}$ was studied for Hg (Fig.2 and Fig.3).

Table 1. Comparison of 4 methods for wet digestion

\begin{tabular}{|l|l|l|l|l|}
\hline & $\mathrm{HNO}_{3}+\mathrm{H}_{2} \mathrm{O}_{2}+\mathrm{HClO}_{4}$ & $\mathrm{HNO}_{3}+\mathrm{H} 2 \mathrm{SO}_{4}$ & $\mathrm{HNO}_{3}$ & $\mathrm{CCl}_{3} \mathrm{COOH}$ \\
\hline $\mathrm{Hg}$ & $95.82 \pm 1.14$ & $92.50 \pm 0.50$ & $87.23 \pm 0.92$ & $50.20 \pm 1.50$ \\
\hline $\mathrm{Pb}$ & $88.73 \pm 0.63$ & $80.99 \pm 1.13$ & $82.45 \pm 0.69$ & $88.11 \pm 0.89$ \\
\hline $\mathrm{Cd}$ & $78.09 \pm 0.79$ & $74.15 \pm 0.94$ & $70.34 \pm 1.34$ & $67.15 \pm 1.47$ \\
\hline
\end{tabular}

Table 2. Effect of dilution on recovery $(n=3$, recovery $=$ mean \pm SD)

\begin{tabular}{|l|l|l|l|l|}
\hline & $10 \mathrm{ml}$ & $25 \mathrm{ml}$ & $50 \mathrm{ml}$ & $100 \mathrm{ml}$ \\
\hline $\mathrm{Pb}$ & $54.78 \pm 1.76$ & $88.73 \pm 1.13$ & $90.45 \pm 2.34$ & $95.20 \pm 0.49$ \\
\hline $\mathrm{Cd}$ & $62.25 \pm 1.17$ & $78.15 \pm 1.94$ & $81.14 \pm 1.34$ & $92.55 \pm 0.47$ \\
\hline
\end{tabular}

Table 3. Comparison of 2 methods for Mercury

\begin{tabular}{|l|l|l|}
\hline $\begin{array}{l}\text { Mercury } \\
\text { added } \\
(\mu \mathrm{g} \mathrm{Hg})\end{array}$ & $\begin{array}{l}\text { Method 1 } \\
\text { recovery } \\
\text { mean } \pm \text { SD }\end{array}$ & $\begin{array}{l}\text { Method 2 } \\
\text { recovery } \\
\text { mean } \pm \text { SD }\end{array}$ \\
\hline 0.05 & $87.99 \pm 5.28$ & $96.75 \pm 5.93$ \\
\hline 0.1 & $84.03 \pm 2.43$ & $95.08 \pm 8.51$ \\
\hline 0.2 & $88.84 \pm 7.26$ & $98.40 \pm 2.77$ \\
\hline 0.5 & $88.82 \pm 1.14$ & $98.00 \pm 1.73$ \\
\hline 1 & $86.35 \pm 2.06$ & $97.66 \pm 2.03$ \\
\hline
\end{tabular}

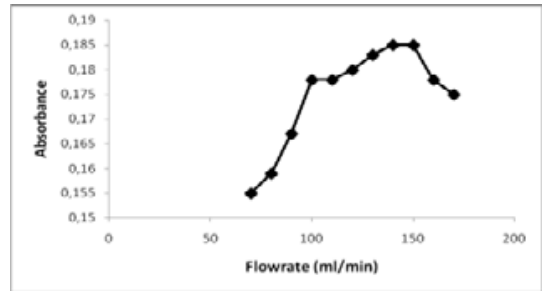

Fig. 2. The effect of flowrate on the absorbance signal of $\mathrm{Hg}$. 
The effect of other ions on the preconcentration and determination of analytes was examined.

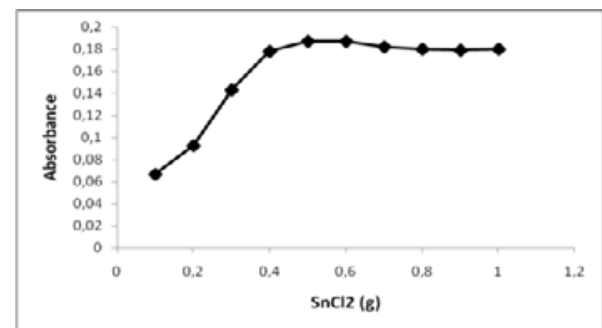

Fig. 3. The effect of $\mathrm{SnCl}_{2}$ on the absorbance signal of $\mathrm{Hg}$.

The concentration of metals in urban and rural mothers samples was investigated and the maximum concentrations were found in urban mothers samples. Fig.4 summarized the results and indicates the concentration of metals in the human breast milk samples of Isfahan.

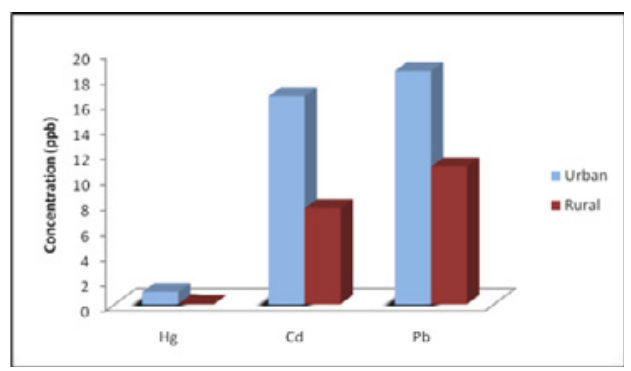

Fig. 4: The concentration of metals in breast milk of urban and rural mothers

\section{Conclusion}

The results show a correlation between the amount of toxic metals in the mother's milk samples and amount of these elements in environment and food. Smoking and dietary habits were the main factors related to heavy metal levels in breast milk. Our results entail the need to survey these pollutants in milk. It can be concluded that this method can be used for inexpensive and simple evaluation of metals contaminants in milk samples.

\section{References}

Bottcher M, Hoffmann E.M, Schunk W. Problems of exposure to organic mercury compounds in pregnancy. Z Gesamte Inn Med 1987; 42:141-143.

Ettinger A.S, Tellez-Rojo M.M, Amarasiriwardena C, Peterson K.E, Schwartz J.Aro, A, et al. Influence of maternal bone lead burden and calcium intake on levels of lead in breast milk over the course of lactation. Am J Epidemiol, 2006; 163:48-56.

Gulson B.L, Mizon K.J, Korsch M.J, Palmer J.M, Donnelly J.B. Mobilization of lead from human bone tissue during pregnancy and lactation - a summary of long-term research. Sci. Total Environ 2003; 303:79-104.

Jarup L, Berglund M, Elinder C.G, Nordberg G, Vahter $M$. Health effects of cadmium exposure - a review of the literature and a risk estimate. Scand. J Work Environ Health 1998; 24 (Suppl 1):151.

Jarup L. Hazards of heavy metal contamination. Br Med Bull 2003; 68:167-182.

Massaro EJ, Handbook of human toxicology, CRC Press, New York, 1997.

Nishijo M, Nakagawa H, Honda R, Tanebe K, Saito S, Teranishi H, Tawara K. Effects of maternal exposure to cadmium on pregnancy outcome and breast milk. Occup Environ Med 2002; 59:394-396.

Oskarsson A, Schultz A, Skerfving S, Hallen IP, Ohlin $\mathrm{B}$, Lagerkvist BJ, Total and inorganic mercury in breast milk in relation to fish consumption and amalgam in lactating women. Arch Environ Health, 1996, 51:234-241.

Schoeters G, Den H.E, Zuurbier M, Naginiene R, van den H.P, Stilianakis N, Ronchetti R, Koppe J.G. Cadmium and children: exposure and health effects. Acta Paediatr 2006; 00 (Suppl 95):50-54.

Solomon G.M, Weiss P.M. Chemical contaminants in breast milk: time trends and regional variability. Environ Health Perspect 2002; 110:A339-A347.

Vather M, Berglund M, Akesson A, Lidén C. Metals and Women's Health. Health Environ Res 2001; 88:145-155.

Wong SL, Lye EJ. Lead, mercury and cadmium levels in Canadians. Health Rep 2008; 19:31-6. 